$\xi=1$ 圆

\title{
PQ improvement of Micro-Grid by Using DG and Power Quality Conditioner with BESS
}

\author{
Chandra Sekhar Mishra ${ }^{1}$, Ranjan Kumar Jena ${ }^{1}$, Soumya Ranjan Nayak ${ }^{2}$ \\ ${ }^{I}$ Department of Electrical Engineering, College of Engineering and Technology, Bhubaneswar, Odisha, India \\ ${ }^{2}$ Department of Computer Science and Engineering, K L University, Vaddeswaram, Andhra Pradesh, India \\ *Corresponding author E-mail:getmechinu@gmail.com
}

\begin{abstract}
DG Grid interfaced system has been focused through this paper. The objective is to improve power quality of the grid, which was polluted by various means. The improvement of power quality of the micro grid includes uses of a specially designed DG, BESS and Power Quality conditioner. The system consists of a two-stage power conversion. Solar PV supplies power for both DC and AC loads. Manufacturer datasheet is used for modeling the PV panel. In order to keep the BUS voltage stable a BESS is joined to DC BUS through power electronic converter, which is used to absorb the excess power whenever production is high and deliver power to the load on low production. The system continues to supply the local loads, incase of grid discontinuity. Thus it eliminates threats of islanding. This paper also focuses on control and stability of DC bus voltage and energy management scheme. The project uses Matlab/Simulink platform for efficient verification. For power quality improvement of Micro Grid it uses 3leg inverter, which is coupled with SPV and MPPT with Battery storage, which is used as compensator for the whole system. For prevention to reduce voltage current and power flow between DG and Grid, it is necessary to have an optimum control. Through the adjustment of power circulation between shunt paired DG ensures current voltage and power on micro grid. +ve, -ve and Zero sequence components of currents and voltage can be adjusted by the suggested methodology in Grid tied DG system. The said PQC have multiple uses. Firstly as a power converter and secondly as a shunt APF for harmonic compensation on voltage, current and power (both active and reactive) for both balanced and unbalanced loads in the Grid tied DG system. It also cares for the neutral conductor. Either individually or in grid connected mode all the above objectives can be achieved. For the entire Grid, it is realized that after compensation three phase four wired un-balance loads looks as balanced linear resistive load for the Grid. All these task significantly replicated on MATLAB/Simulink. After compensation the total harmonic distortion on input voltage and current reduced drastically. IEEE519 in the range of 5\% suitably accepts it.
\end{abstract}

Keywords: Micro Grid, DG Inverter, Power quality, APF, battery energy stor-age system (BESS), energy management (EM), Microgrids, MPPT.

\section{Introduction}

A Micro-grid is the interconnection of a group of interrelated burdens and DG inside a well defined margin regarding the grid and can be connected or detached from the main grid and operate both in interconnected mode or islanded mode. Due to unbalanced burdens interfacing is a major concern for everybody. Power generated from crude oil and coals have several drawbacks and limitations. The drawbacks include emission of greenhouse gases, global price hike and the most important part is limitation of fossil fuel and increase in cost affects almost all part of the economics. But the demand of these conventional sources is increasing day by day. So power generation from non-conventional sources is nowadays is a great challenge and a matter of concern for everybody. In this context solar energy is the best alternative for reduce reliance on conventional sources. Most of the renewable sources are environmental friendly abundantly available by nature and can be used as future energy. One should not avoid the intermittent nature of these sources and their conversion efficiency while considering these sources as an alternative of the conventional sources. For solar photovoltaic system the main drawback is its irradiation and temperature dependency. So solar PV with BESS (Battery Energy Storage System) with grid connected mode or islanded mode can be the best solution for these issues to drive loads and simultaneously improve quality in power demand. A well-organized SPV with efficient control strategy can be used to assure demand by the connected loads. A bundle of literature also available in this context of simulation modeling. Loads of the consumers are significantly affected by several power quality problems like distorted voltage and harmonics [6][9]. Several methodologies are adopted time to time for compensating this harmonic content [8]. Some of these techniques are listed below. Load balancing, mitigation of harmonic content in both current and voltage, compensation on reactive power, regulation of voltage at point of common coupling are achieved by DSTATCOM. Accurate control mechanism is a need to achieve these entire said tasks and the important aspect is that all should suit the international standard. [16] [22][12] [25] [4][21] [24] [29] [27] [23]. APF with CSC control mechanism for medium voltage to eliminate harmonic well stated by Terciyanli [2]. A VSC platform on STATCOM is also advantageous than CSC based platform [33] [1]. Allmeling in [10] discussed a shunt APF that uses a control mechanism to compensate harmonic content in grid. A theory based on PQ can be considered as fortitude for shunt APF [3]. The control mechanism, such as

I Cos $\varphi$ mechanism, direct control of power, predictive control procedure, reactive current control mechanism [13][14][11][7][19] are also stated in various literatures are focused previously to 
overcome these difficulties for DG grid interface system. Some of the adaptive control mechanism with load approximation and characterized triangle function also stated in literature [28][20]. Similarly observer base composite strategy also listed time to time to overcome these difficulties for DG grid interfaced system [26]. A DSP mechanism based control on APF also listed in[31]. Bhuvaneswari in [17] reported on tightfitting of waves and

I $\operatorname{Cos} \varphi$ approach for power frequency revision. Similarly synchronous control strategy, current identical method, power equalization method, matching resistance method also comes into picture by al.et. Lin [30][32]. In the said topology the performance is quite unusual for high voltage application. Synchronous method of harmonic content detection explained by Ram and Syed [15] also not able to compensate harmonic to a accepted limit. That's way it is evident that connection of series and shunt specially designed mechanism with power electronic converter can effectively use to overwhelm these task on micro grid. Main Grid and Micro grid generally connected to load centers and cause harmful influence to both load and the connected grid. So some sensitive loads may severely affected whose requirement is pure sinusoidal wave shape. It is necessary that under these unfavorable conditions Grid should disconnect from AC main and isolate the faulty part from the healthful part by an autonomous control mechanism [5]. Auto re-closers can employed for less disturbed condition otherwise not. For harmonic mitigation purposes one should obviously introduce a well-designed compensator with its control strategy to overcome these nonlinearity. These difficulties are more prominent due to low value of line impedance between micro grid and main grid. Unnecessary huge stress on line conductors and in incoming inverter may be the result due to these control mechanism. Some times these influence is so high time it malfunction the devices used to operate systematically in $3 \Phi 4$ wire systems. Zero sequence component of current may flow and can harmful in these associated strategies. To overcome these difficulties the said project which is a combination of DG grid interface at PCC of $3 \Phi$ 4-wire type. The DG itself able to compensate the all desired task like load voltage sharing, overcurrent bypass, line compensation, reactive power compensation, power factor improvement, total harmonic distortion care etc. can be achieves by these topology. Distributed generator which is a SPV with MPPT and specially designed inverter is a section of Micro Grid can able to mitigate all these nonlinearity in a sophisticated manner. It has a provision to control neutral current on respective conductor. The said task can perform independently or in Grid connected mode and able to perform satisfactorily. Grid tied DG system with BESS based on Clark's transformation introduced to extract current reference. The control mechanism and this specially designed novel methodology are discussed as follows:

The manuscript is structured as follows:

The section II exhibits Micro Grid and its Architecture interfaced with main Grid. Mechanism and Control methodology discussed III. Part. Detailed simulation on MATLAB/Simulink presented in Section IV. Analysis of result and THD analysis for the methodology discussed in part V. lastly the conclusion discussed in part VI.

\section{AC/DC Micro-Grid Architecture}

Figure 1 shows the proposed work of a Grid tied DG system with BESS.

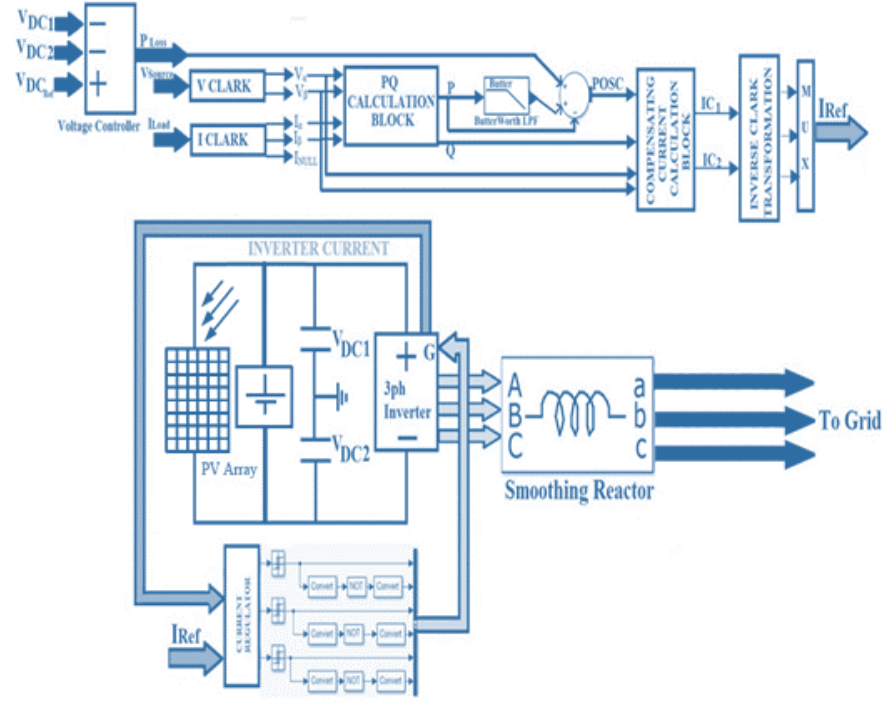

Fig. 1. Schematic arrangement of DG Grid Interfaced system

The topology show in above figure consists of SPV as DG, Battery Energy Storage System, Controller, and Several types of DC and $\mathrm{AC}$ burdens. The Distributed Generator is connected to the DC-to-DC Boost Converter. To operate the entire system a $\mathrm{P} / \mathrm{O}$ based MPPT is employed for efficient tracking of SPV output. The Battery energy storage system has following function as indicated in Power Management.

\section{A. Power Management in Grid connected Fashion:}

If Distributed Generator energy is ample for supplying the DC AC burdens when the battery is not fully charged, the remaining energy lead to AC mains and Energy Storage block is coordinated at charging mode.

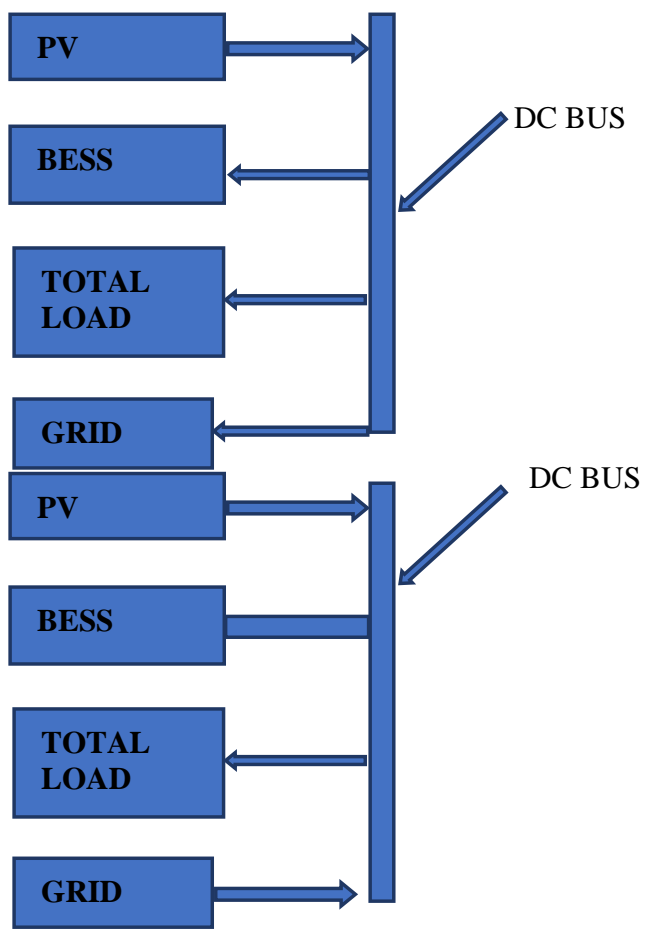

When the Distributed Generator energy inadequate for Supplying the DC AC burden then battery actuates. When, the battery is not wholly charged required power is contributed from AC grid. When Battery becomes fully charged would remove after the DC LPP as stand-by mode to discharge in islanding condition. II. B. Power Management in Islanded Mode: 
Similarly if Distributed Generator energy is ample enough for supplying DC AC burdens and battery when battery is not entirely exciting, the rest power is used for the utility loads, as Grid is absent.
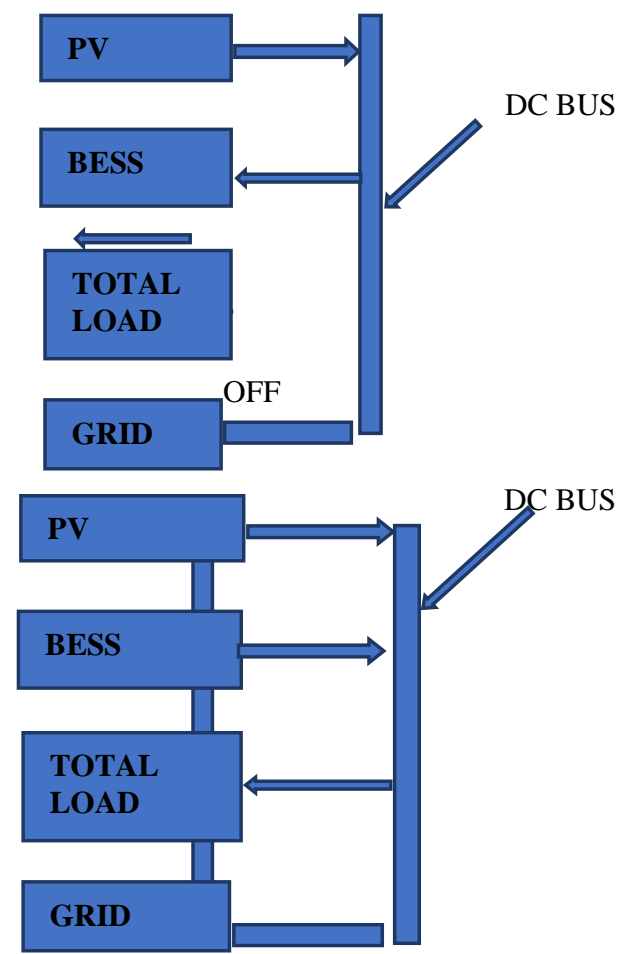

If DG energy is insufficient to supply the loads the battery should take care of the connected loads and continue to give supply till its SOC level falls below $60 \%$.

\section{Control of PV system}

To draw maximum power efficiently from SPV, P/O based MPPT is included in the Boost Converter as the availability of solar energy is intermittent in nature. The MPPT controller can be driven by a direct duty ratio error. The Direct duty ratio error can be used directly as a control parameter for MPPT tracking.

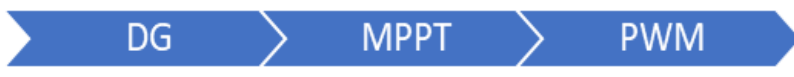

Fig. 1. MPPT control with direct duty ratio

\section{Control of Grid- Connected Converter}

A universal AC to DC converter (bidirectional) can be employed for exchange of power to/ from Grid system to DG system. The objective of this mechanism is to maintain DC voltage at a definite limit by using a PI controller and feedback mechanism. A realtime DC voltage measurement and comparison with the reference signal generate error which is used to control Pulse width modulated Inverter. The Voltage of DC-link actually targets the Power stream. When in Case of DC Burden Current $\mathrm{I}_{0}$ is +ve that is the rectifier operation and the condenser is settled and Signal Error made +ve.

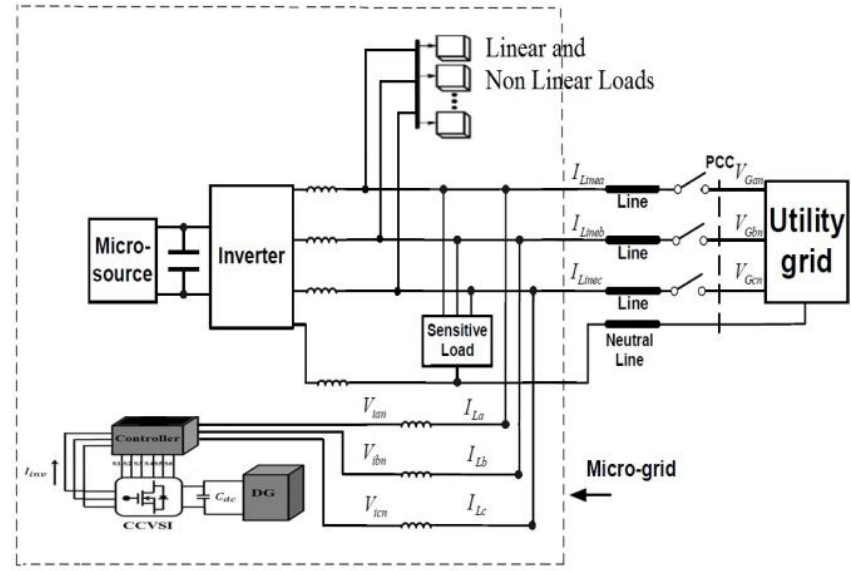

Fig. 2. proposed system with varius loads and PCC

Here control lump gets energy from resource by engendering the corresponding Pulse Width Modulated gestures to devices. Conversely, when I0 flatters or -ve called as operated in inversion mode, condenser that is overcharged. The Signal of error demands to the controller for discharging the condenser to return power towards AC circuit.

\section{Control of BESS:}

The function of DC to DC bidirectional converter is to interface Battery storage unit to DG for improving the performance of the grid tied DG system. The word bidirectional means the combination of buck converter and boost converter which operates on necessary gate pulse. Again this bidirectional converter operates during the period of extra power and generated PWM signal drives the controller to buck mode and suitably charges the battery unit. In case of power deficit the PWM signal drives the bidirectional converter to boost mode and steps-up the battery output for extraction of Energy as shown in figure 4.

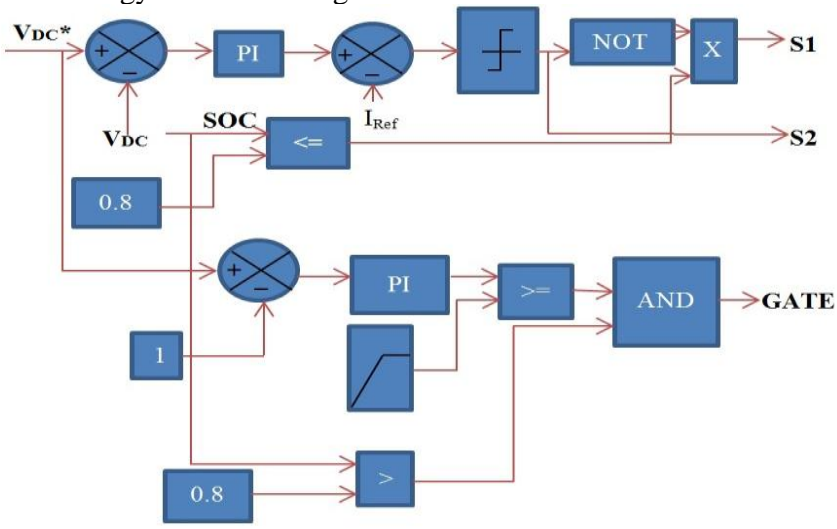

Fig. 3. Battery bidirectional DC-DC converter control

The battery reference current $I_{\text {Bref }}$ can be calculated using equation given as follows:

$I_{B_{-} \text {ref }}=\frac{P_{B-\text { Dref }}}{B_{-} \text {Cref }} / V_{B}$

The calculation of the suitable passive parameter like inductor and capacitor can be find out by using the equation are as follows:

$L=\frac{V_{B a t} *\left(V_{D C L i n k}-V_{B a t}\right)}{I_{B a t t * f_{S} * V_{D C \text { Link }}}}$ 


\section{Buck mode Condencer $=\frac{K_{L^{*}} I_{B a t}}{s v f_{s} * V_{B a t t}[R i p l e]}$ \\ Boost mode Condencer $=\frac{D_{\text {Bost } * I D C \text {. Link }}}{f_{s} * V_{D C} \text { Link }[\text { Riple }]}$}

The governing power management technique suitably maintains both charging and discharging of battery at the time of deficit and excess of DC and AC Load power.

Table I: Input/output of proposed power management

\begin{tabular}{|l|l|}
\hline Abbreviations & Description \\
\hline$P_{L}$ & Load Power \\
\hline$P_{G}$ & Grid Power \\
\hline$P_{P V}$ & PV Power \\
\hline SOC & Battery State of Charge \\
\hline$P B_{D \text { ref }}$ & Battery discharging reference \\
\hline$P B_{C \text { ref }}$ & Battery Charging reference \\
\hline$P_{G I}$ & Grid Reference Power \\
\hline$P_{G I}$ & Power Injected to Grid \\
\hline$P_{G S}$ & Power Supplied from Grid \\
\hline$I_{B}$ & Battery Charging Current \\
\hline$I_{B \max }$ & Maximum Battery Charging Current \\
\hline
\end{tabular}

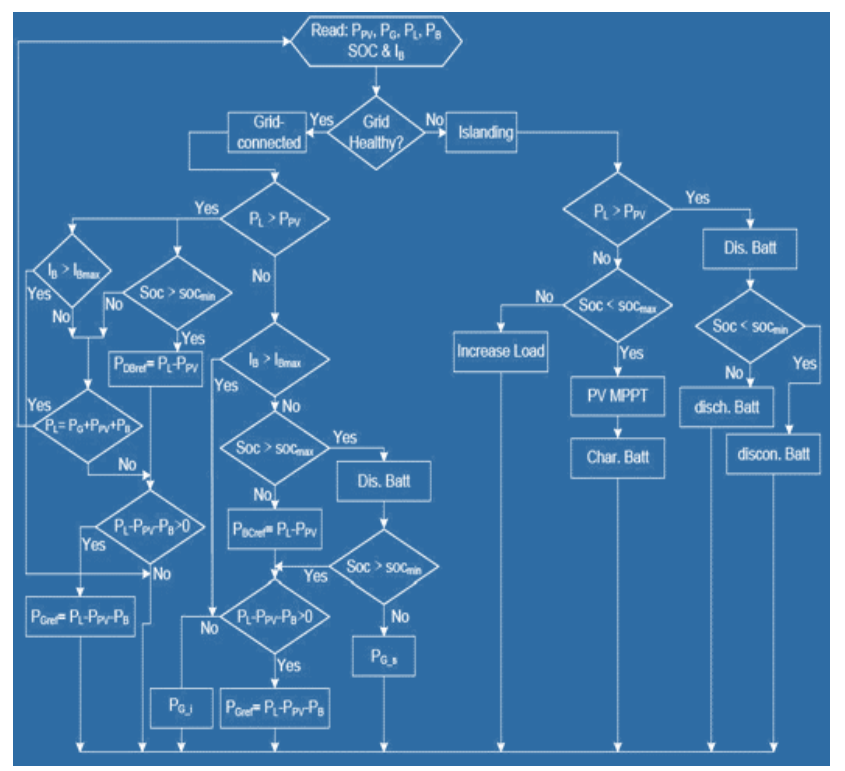

Fig. 4: Proposed power management flow chart

\section{Control Mechanism}

It is consider as the intelligence of every power system. These are the steps for satisfactory operation of the system. Potential transformers and current transformers, Voltage, current sensors forage necessary system stricture such as current and voltage value. PQ theory is the basic building block of the said topology, which is incorporated, with several arrangements of filters. From the below equation the gate signal is generated and latter it is used to firing the DG inverter and also compared with the set current value. That set current value mostly the PI controller output. Here a adaptive PI controller can be taken to operate satisfactorily. The Preset assessment of both current and voltage interrelated with two inputs of the controller. This will generate fault or error between 2 inputs and the preset values a signal is produced. Compensating current calculation is the important part of any control strategy. Here in this project it is based on PQ theory (Clark's Transformation). These are some basic equations for grid tied DG system with CCVSI, which is a necessary portion of the procedure.

$$
\left[\begin{array}{l}
V \alpha \\
V \beta
\end{array}\right]=0.8165\left[\begin{array}{lll}
1 & -0.5 & -0.5 \\
0 & 0.866 & -0.866
\end{array}\right] \times\left[\begin{array}{l}
V_{R} \\
V_{Y} \\
V_{B}
\end{array}\right]
$$

$$
\left[\begin{array}{l}
V_{R} \\
V_{Y} \\
V_{B}
\end{array}\right]=0.8165\left[\begin{array}{ll}
1 & -0.5 \\
-0.5 & 0.866 \\
-0.5 & -0.866
\end{array}\right] \times\left[\begin{array}{c}
V \alpha \\
V \beta
\end{array}\right]
$$

$\left[\begin{array}{l}I \alpha \\ I \beta\end{array}\right]=0.8165\left[\begin{array}{lll}1 & -0.5 & -0.5 \\ 0 & 0.866 & -0.866\end{array}\right] \times\left[\begin{array}{l}I_{R} \\ I_{Y} \\ I_{B}\end{array}\right]$

$\left[\begin{array}{l}I_{R} \\ I_{Y} \\ I_{B}\end{array}\right]=0.8165\left[\begin{array}{ll}1 & -0.5 \\ -0.5 & 0.866 \\ -0.5 & -0.866\end{array}\right] \times\left[\begin{array}{l}I \alpha \\ I \beta\end{array}\right]$

$$
\left[\begin{array}{l}
P \\
Q
\end{array}\right]=\left[\begin{array}{ll}
V & V \\
V & V
\end{array}\right] \times\left[\begin{array}{l}
I \\
I
\end{array}\right]
$$

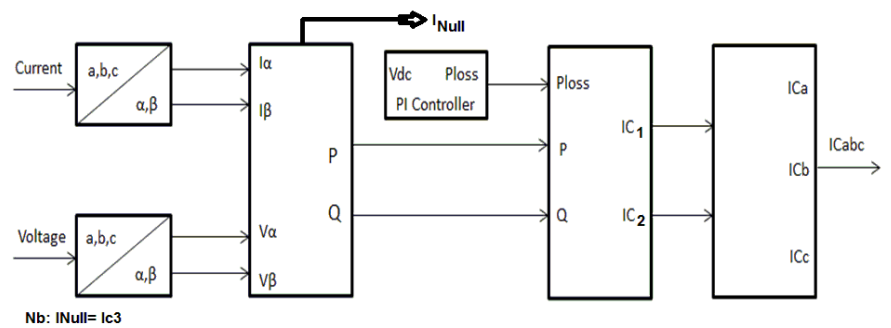

Fig. 4. Control Mechanism

$\operatorname{ActivePower}(P)=[(V \times I)+(V \times I)]$

$\operatorname{Re}$ activePower $(Q)=\left[\begin{array}{ll}V \times I) & (V \times I)\end{array}\right]$

$P_{\text {loss }}=K_{P}\left\{V_{d c r e f} \quad\left(V_{d c}\right)\right\}+K_{i} \quad\left\{V_{d c r e f} \quad\left(V_{d c 1}\right)\right\} d t$

$I_{C 1}=\frac{1}{V^{2}+V^{2}}\left(p_{\text {Modified } V+Q V}\right)$

(12)

$$
I_{C 2}=\frac{-1}{V \alpha^{2}+V \beta^{2}}\left(p_{\text {Modified }}{ }^{\alpha} V \beta+Q \times V \alpha\right)
$$$$
I c_{3}=I_{\text {Null }}
$$

Where $P_{\text {Modified }}$ is states as above.

$$
\begin{aligned}
& I_{C . A}=0.816 \quad\{I C 1+(0.707 \quad I C 3)\} \\
& I_{C . B}=0.816 \times\left\{\frac{I_{c 1}}{2}+\frac{\sqrt{3}}{2} I_{c 2}+\left(0.7072 \times I_{c 3}\right)\right\} \\
& I_{C C}=0.816 \times\left\{\frac{I_{c 1}}{2} \frac{\sqrt{3}}{2} I_{c 2}+\left(0.7072 \times I_{c 3}\right)\right\}
\end{aligned}
$$

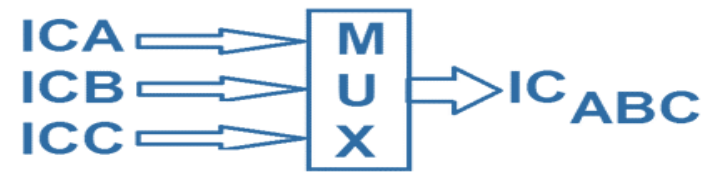

Fig. 5. Reference current Calculation 


\section{Operation of Hysteresis Control Block}

$I C_{A B C}$ can be reflected as Reference to Hysteresis control Slab. If Current reference for phase $\mathrm{R}$ is greater than Inverter current of phase $\mathrm{R}$, we get a pulse as a yield, which is a triggering pulse of switch 1. If it is not true another switching pulse generated for switch 2. Similarly If Current reference for phase $Y$ is greater than Inverter current of phase $\mathrm{Y}$, we get a pulse as a yield, which is a triggering pulse of switch 3 . If it is not true another switching pulse generated for switch 4.lastly Current reference for phase B is greater than Inverter current of phase B, we get a pulse as a yield, which is a triggering pulse of switch 5. If it is not true another switching pulse generated for switch 6 . The output switching pulse of $\mathrm{H}$. controller again consumed by the $3 \Phi$ Bridge. For feed back purposes PI controller is used and generates $P_{\text {Loss }}$, which is consider as DC voltage controller. This $P_{\text {Loss }}$ is summed with real power calculated previously. The above said task is operated in a recurring manner to give desired output.

To get the corrected value of both proportional gain and integral gain precisely, we can use Matlab /Simulink with an programmed PI tuning feature. In this topology, we use these P gain and I gains values correctly programmed according to the deviation of nonlinear loads. To regulate power at load PCC is the purpose to be served by the DG-Grid interface terminology. Accordingly to the necessity of the load, this power exchange takes place in between the Grid. In case of highly nonlinear loads the inverter is able to modify the waveform of voltage and current in the manner that achieves of purely resistive characteristic by adjusting harmonics or glitches on neutral conductors limits up to zero.

To modify the grid current's structure same as a clean resistive load, the switching methodology of DG inverter is modified according to the load necessity and introduces required quantity of harmonic current. The output of DC link voltage can be given or taken with respect to active power management for grid tied DG system. For synchronization purposes PLL is used.

$$
I_{R}=\operatorname{Sin} \boldsymbol{\theta}, I_{Y}=-\operatorname{Sin} \boldsymbol{\theta}-\frac{2 \pi}{3}, I_{B}=\operatorname{Sin} \boldsymbol{\theta}+\frac{2 \pi}{3}
$$

For removal of ripples from a butter-worth LPF circuit DG voltage $\mathrm{VDC}_{1}, \mathrm{VDC}_{2}$ can be consumed Yield of DG voltage in comparison with respect value (VDC ${ }^{\mathrm{n}}$ a fixed amount) and then consumed by an automatic PI controller in order to generate a fixed DC voltage not in respect of the load profile. There is a necessity of proper tuning controller is quiet satisfactory. The Fundamental load power's instantaneous value is to be termed as power ${ }_{\mathrm{LF}}$. The load reactive powers instantaneous value is the 2 nd term power LQ, the harmonic load power instantaneous value is the 3rd term that represent $\operatorname{power}_{\mathrm{LHar}}$. In this project initially the value of $\mathrm{Kp}=1 / 5$ and $\mathrm{Ki}=1 / 20$ are taken.

$$
\begin{aligned}
& I_{R}^{*}=\operatorname{Im} X I_{R} \quad ; \quad I_{Y}^{*}=\operatorname{Im} X I Y \quad ; \quad I_{B}^{*}=\operatorname{Im} X I B ; \\
& I_{\text {neutral }}^{*}=\text { Zero } I^{*} R, I^{*} Y, I^{*} B \text { and } I_{\text {neutral }}^{*} \text { are coupled with }
\end{aligned}
$$
converter currents, $\mathrm{I}_{\mathrm{CONV}} \mathrm{R}, \mathrm{I}_{\mathrm{CONV}} \mathrm{Y}, \mathrm{I}_{\mathrm{CONV}} \mathrm{B}$ and $\mathrm{I}_{\mathrm{CONV}} \mathrm{N}$ for computing the current errors and fed to a Hysteresis based regulator for generating required switching gate pulse from S1 to S6.

$$
\begin{gathered}
I_{\text {Load }}(t)=\underset{\text { har }=1}{I_{\text {harmonic }}} \sin \left(h_{\text {ar }} t+\text { harmonic }\right)= \\
I_{f 1} \sin \left(t+I_{h=1} I_{\text {harmonic }} \sin \left(h_{\text {ar }} t+\text { harmonic }\right)\right.
\end{gathered}
$$

$$
\begin{aligned}
& P_{\text {Load }}(t)=V_{\text {Source }}(t) . I_{\text {Load }}(t) \\
& =V_{m} I_{f 1} \sin ^{2} t \cos \left(f_{1}\right)+V_{m} I f_{1} \sin t \cos (t) \sin \left(f_{1}\right) \\
& +V_{m} \sin t \quad I_{\text {har }} \sin \left(h_{\text {ar }} t+{ }_{\text {har }}\right) \\
& =\text { Power }_{\text {harmonic=1 }}(t)+\operatorname{Power}_{L Q}(t)+\text { Power }_{\text {Lharmonic }}(t)
\end{aligned}
$$

\section{Simulation Outcome}

MATLAB/Simulink platform is used to achieve numerous objectives for validating the said topology on 3 phases 4 wired DG Grid interface system.

Table 1

Scheme Limits

\begin{tabular}{|l|l|}
\hline $3 \Phi$ source & $\mathrm{V}_{\mathrm{G}}=40 \mathrm{Volts}, 50 \mathrm{Heartz}$ \\
\hline $\begin{array}{l}3 \Phi \text { Linear and Non Linear load in } \\
\text { volt- amp reactive }\end{array}$ & $\begin{array}{l}500 \mathrm{Watt}, 0.005 \text { Volt-Ampere } \\
\text { Reactive }\end{array}$ \\
\hline DC- Link condenser & 400 micro farad \\
\hline Required Coupling Inductor & 3 numbers of $2.5 \mathrm{mH}$ each \\
\hline
\end{tabular}

For clarity the Per phase resistance of line and per phase reactance of line is taken as $1 \Omega$ and $1 \mathrm{mH}$ respectively. In this project the resistive -inductive loads increases up to $70-80 \%$ of full load through a phase controlled rectifier switch used for investigation purposes at load Point of common coupling. The consequence of this nonlinearity of at several gate pulses can now be reflected on source. The wave form of current and voltage changes and the high harmonic content is the result and causes power quality problem. The control strategy and proper synchronization of SPV based distributed generator with P/O MPPT introduces required amount of harmonic to the utility grid for the improvement of THD value both in current and voltage waveform.

\section{A Practical Case:}

TABLE I. SYSTEM PARAMETER SPV Inverter terminology

\begin{tabular}{|l|l|}
\hline \multicolumn{2}{|c|}{ SPV Inverter terminology } \\
\hline Peak DC Power & 1200 Kilo Watt \\
\hline Peak DC Supply voltage & 800 Volt \\
\hline Esteemed DC Value & 650 Volt \\
\hline Filter resistance and Inductance & $\begin{array}{l}\text { L=200 } \\
\text { Ohm, Henery , R=1.5 m }\end{array}$ \\
\hline Transformer & $1.5 \times 10^{6}$ VA, 50 Hz \\
\hline Rated Power & 1 Mega watt \\
\hline Linked DC Voltage & 1200 volt \\
\hline 2 number of DC link Condencers & $4000 \mu \mathrm{F}$ \\
\hline Inductance for coupling purposes & $2 \mathrm{mili} \mathrm{Henery}$ \\
\hline Frequency (Sampling Value) & $5 \mathrm{Kilo} \mathrm{Heartz}$ \\
\hline Specification of Grid & \\
\hline Voltage of Source & $440 \mathrm{Volt}$ \\
\hline Frequency of Source & $50 \mathrm{Heartz}$ \\
\hline Ls & $40 \mathrm{mH}$ \\
\hline Xs/Rs & 8 \\
\hline
\end{tabular}

TABLE II. LOAD SPECIFICATION

\begin{tabular}{|l|l|}
\hline Load Specification & A phae resistance $=50 \mathrm{ohm}$, \\
Unbalanced RL Load & A phae reactance $=200 \mathrm{mH}$, \\
& B phae resistance $=75 \mathrm{ohm}$, \\
& B phae reactance $=225 \mathrm{mH}$, \\
\hline
\end{tabular}




\begin{tabular}{|c|c|}
\hline \multicolumn{2}{|l|}{ Load Specification } \\
\hline & $\begin{array}{l}\mathrm{C} \text { phae resistance }=25 \mathrm{ohm}, \\
\mathrm{V} \text { phae reactance }=175 \mathrm{mH},\end{array}$ \\
\hline Non Linear Load1 & $125 \mathrm{ohm}$ \\
\hline ЗФ Diode rectifier Load & $300 \mathrm{mh}$ \\
\hline $\begin{array}{l}\text { Non Linear Load2 } \\
\text { Control Rectfier Load }\end{array}$ & $\begin{array}{l}\text { P Active }=10 \mathrm{~kW} \\
+ \text { ve VAR }=300 \\
\text {-ve VAR }=150\end{array}$ \\
\hline Linear Load & $\begin{array}{l}\text { P Active }=10 \text { kilo Watt } \\
+ \text { ve VAR }=10 \mathrm{Kvar} \\
\text {-ve VAR }=5 \mathrm{Kvar}\end{array}$ \\
\hline
\end{tabular}
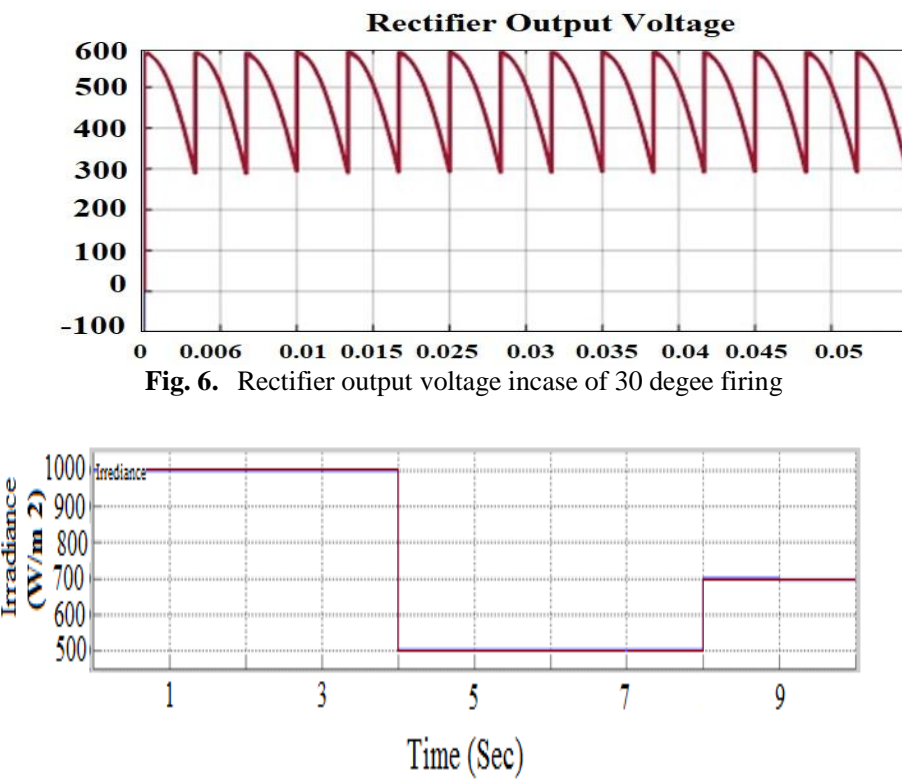

Fig. 7. Irradiance at constant temperature (250c)

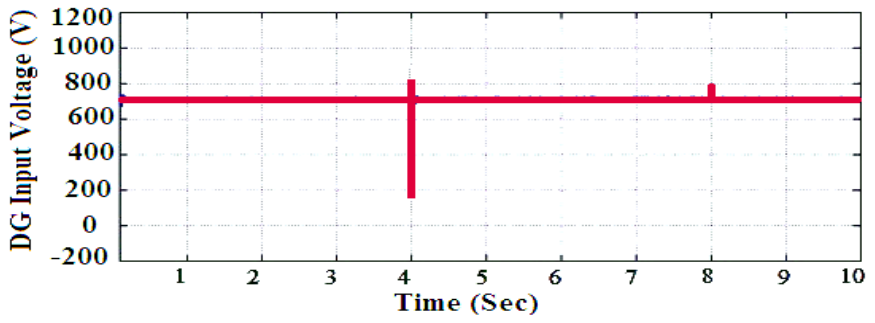

Fig. 8. DG Input Voltage

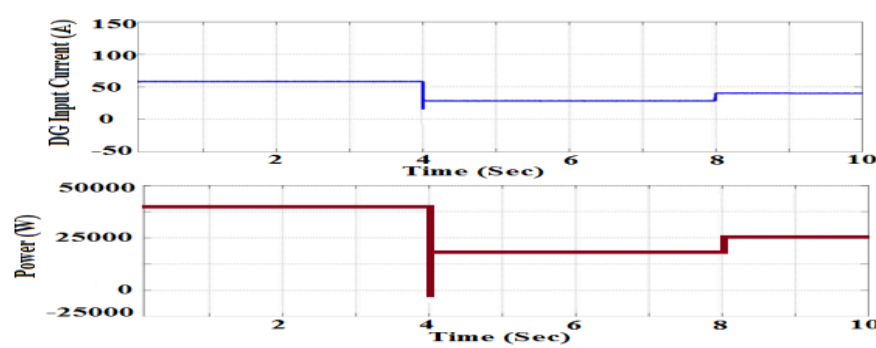

Fig. 9. Simulation result of DG current and Power during change in irradiance

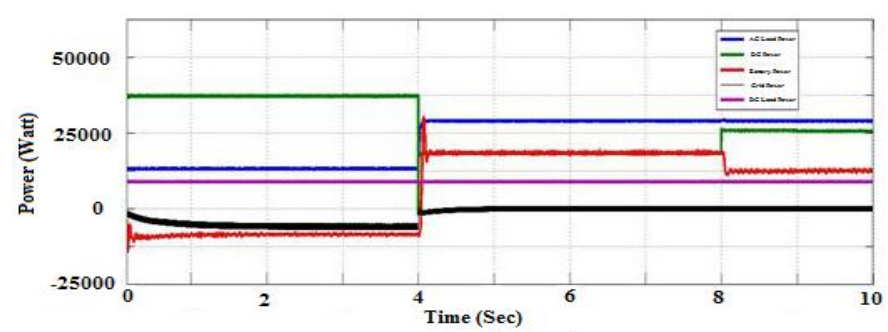

Fig. 10. Simulation result of Power Output during charging

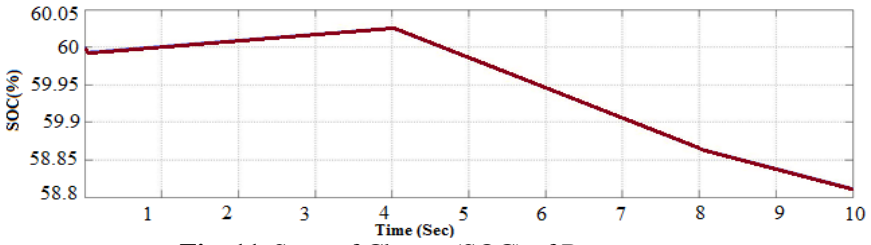

Fig. 11. State of Charge (SOC) of Battery

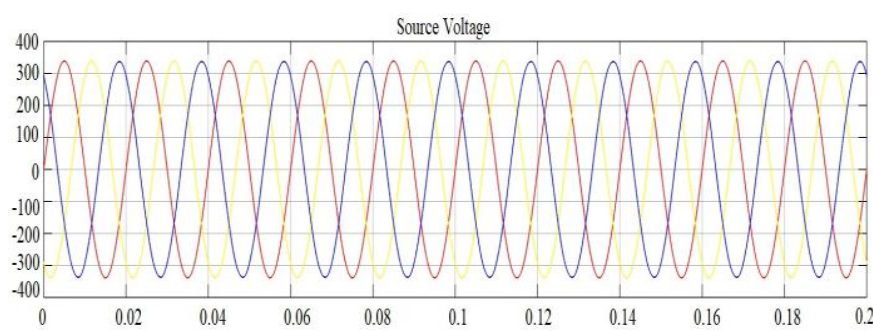

Fig. 12. Source Voltage Without DG
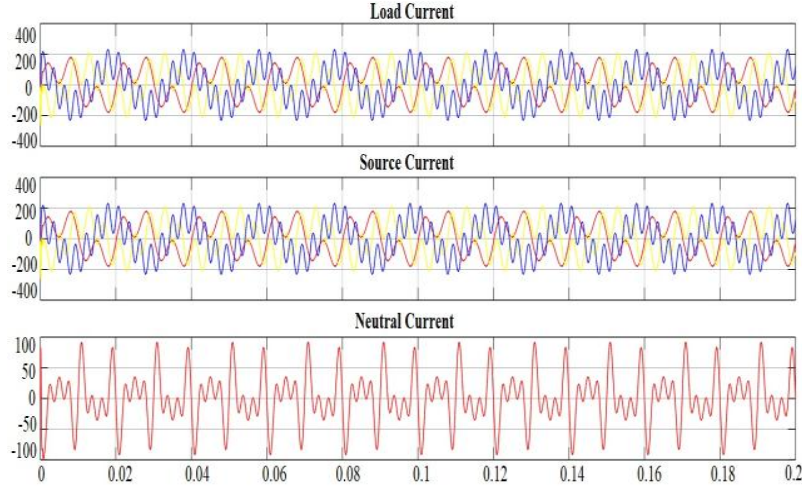

Fig. 13. Load Current, Input Current, Current in Neutra ConductorWithout Distributed Generator

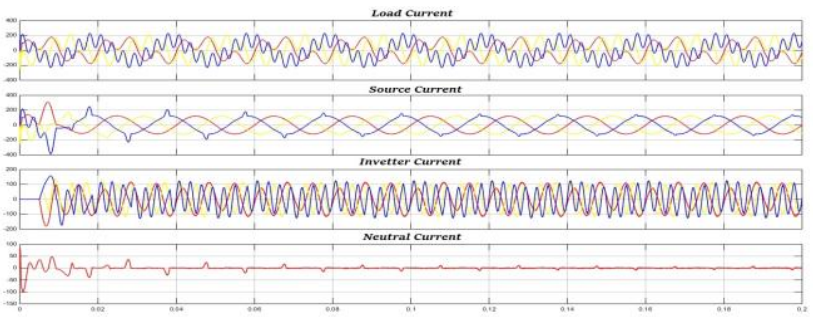

Fig. 14. Burden Current, Input Current, Converter Current and Current in neutral conductor With Distributed Generator
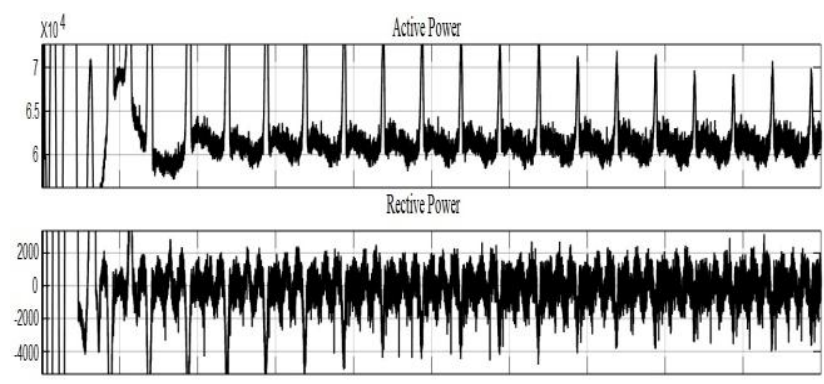

Fig. 15. P Active and P Reactive at 30 Degree Gate Pulse With Distributed Generator

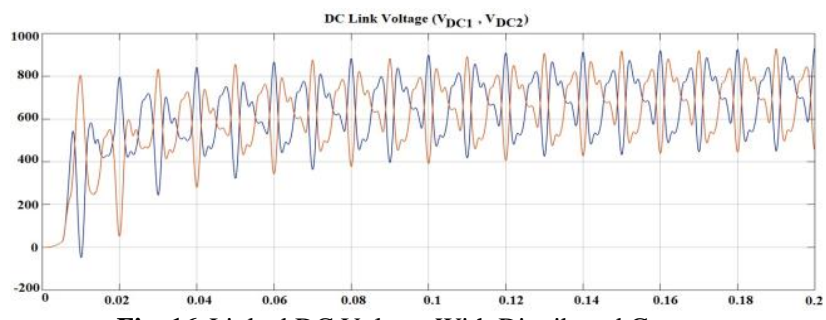

Fig. 16. Linked DC Voltage With Distributed Generator 


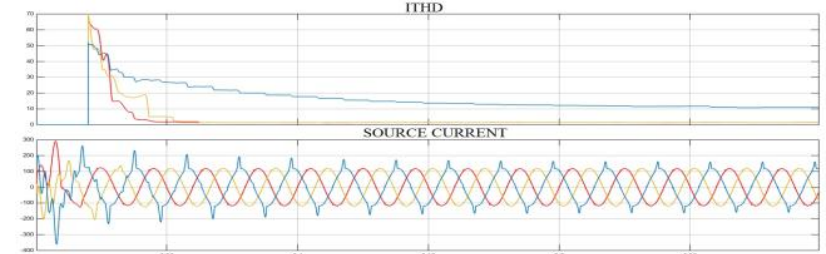

Fig. 17. Current THD Value of Source in 30 Degree Firing With Distributed Generator

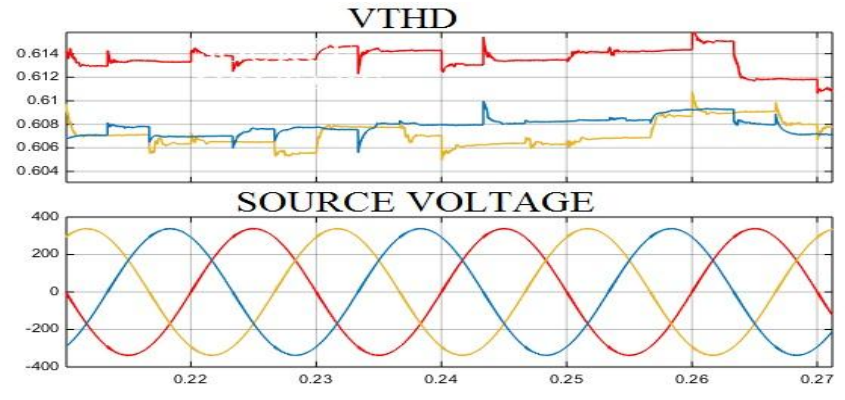

Fig. 18. Voltage THD Value of Source in 30 Degree Firing With Distributed Generator

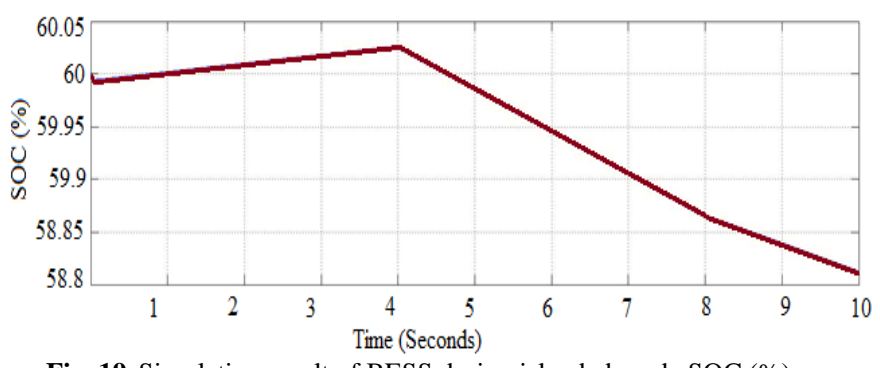

Fig. 19. Simulation result of BESS during islanded mode SOC (\%)

The waveform shown in figure 7,8,910,11,12 Rectifier output voltage incase of 30 degee firing, Irradiance at constant temperature (250c), DG Input Voltage, Simulation result of DG current and Power during change in irradiance, Simulation result of Power Output during charging, State of Charge (SOC) of Battery. Wave shape shown in figure 13, 14,15,16,17,18, 19, 20 are Source Voltage Without DG, Load Current, Input Current, Current in Neutral ConductorWithout Distributed Generator, Burden Current , Input Current, Converter Current and Current in neutral conductor With Distributed Generator, Active Power and Reactive power at 30 Degree Gate Pulse With Distributed Generator, Linked DC Voltage With Distributed Generator, Current THD Value of Source in 30 Degree Firing With Distributed Generator, Voltage THD Value of Source in 30 Degree Firing With Distributed Generator, Simulation result of BESS during islanded mode SOC (\%). It is evident from the above results that the said terminology effectively compensates the abnormality present in both current and voltage in case of $30^{\circ}, 45^{\circ}$ and $60^{\circ}$ firing with different loads (Linear, Nonlinear). By changing the load requirement one can also notice the same type of result presizely. The results shown in above figure meant for a specific load and can be changed depending upon our requirement.

\section{Results Analysis}

TABLE III. RESULT ANALYSIS

\begin{tabular}{|l|l|l|l|l|}
\hline $\begin{array}{l}\text { Nonlinear Burdens } \\
\text { at Different Firing } \\
\text { angle }\end{array}$ & $\begin{array}{l}\text { VTHD } \\
\text { Without } \\
\text { DG }\end{array}$ & $\begin{array}{l}\text { ITHD } \\
\text { Without } \\
\text { DG }\end{array}$ & $\begin{array}{l}\text { VTHD } \\
\text { With DG }\end{array}$ & $\begin{array}{l}\text { ITHD } \\
\text { With DG }\end{array}$ \\
\hline $30^{\circ}$ & $1.59 \%$ & $89.55 \%$ & $0.29 \%$ & $1.18 \%$ \\
\hline $45^{0}$ & $1.67 \%$ & $87.84 \%$ & $0.31 \%$ & $1.07 \%$ \\
\hline $60^{\circ}$ & $1.72 \%$ & $86.78 \%$ & $0.46 \%$ & $1.43 \%$ \\
\hline
\end{tabular}

\section{Conclusion}

In this paper, DC/AC micro grid with $\mathrm{PV}$ power generation and BESS is studied for dc and ac load applications. Control techniques for BESS regulation converter and grid connected bidirectional active rectifier are designed to fulfill the power management capability. The BESS stores power generated by the PV plant enabling to continue operation in maximum power point during high load demand. Similarly, the grid can be used to support the system by supplying additional active power for the load. In this way, the power generation from PV system is effective used to keep the system energy management. DG grid interface system plays a role as an interface among Grid and various types of linear and non-linear load precisely adjust the source current, reactive power etc. Due to the presence of non-linear loads that is connected to micro grid causes distortion and undoubtedly mitigated by the suggested topology precisely. To attain the desired aim, without using particular devices for power quality improvement, we incorporate DG power quality conditioner. For the generation of Gate pulses for DG converter it is controlled by Clark's transformation established principle integrated with hysteresis controller. For reduction of computational burdens Clark's transformation is used. Several studies also carried out with DG and without DG. On every case the source compensation is satisfactory which is quite acceptable to the desired limit.

\section{References}

[1] B. Singh, A. Adya, A.P. Mittal, and J.R.P. Gupta, "Power Quality Enhancement with DSTATCOM for Small Isolated Alternator feeding Distribution System," IEEE International Conference on Power Electronics and Drives Systems, PEDS 2005, pp. 274-279, 2005.

[2] A. Terciyanli, T. Avci, I. Yilmaz, C. Ermis, K. N.Kose, A. Acik, A. S. Kalaycioglu, Y. Akkaya, I. Cadirci, and M. Ermis "A Current Source Converter Based Active Power Filter for Mitigation of Harmonics at the Interface of Distribution and Transmission Systems," IEEE Transactions On Industry Applications, vol. 48, pp. 1374-1386, 2012.

[3] M. Popescu, A. Bitoleanu and V. Suru, "A DSP-Based Implementation of the $\mathrm{p}-\mathrm{q}$ Theory in Active Power Filtering Under Nonideal Voltage Conditions," IEEE Transactions on Industrial Informatics,vol.9, pp. 880-889, July 2013.

[4] A. Ghosh, and G. Ledwich, "Power quality enhancement using custom power devices," Springer International Edition, Delhi, 2009.

[5] M. Prodanovic, and T.C. Green, "Control and filter design of three-phase inverters for high power quality grid connection," IEEE Transactions on Power Electronics, vol. 18, pp. 373-380, Mar 2003.

[6] P. Caramia, G. Carpinelli, and P. Verde, "Power Quality Indices in Liberalized Markets," John Wiley \& Sons, Aug-2009.

[7] B. Singh, and S Kumar, "Control of DSTATCOM using Icos $\Phi$ algorithm", 35th Annual Conference of IEEE Industrial Electronics, pp. 322-327, Novemver 2009.

[8] S.K. Jain, and S.N. Singh, "Harmonics estimation in emerging power system: Key issues and challenges," Electr. Power Syst. Res., vol. 81, , pp. 1754-1766, 2011.

[9] S. Rechka, E. Ngandui, J. Xu and, P. Sicard, "Analysis of harmonic detection algorithms and their application to active power filters for harmonics compensation and resonance damping," Canadian Journal of Electrical and Computer Engineering, vol: 28, pp. 41-51, January 2003.

[10] J. Allmeling, "A control structure for fast harmonics compensation in activefilters," IEEE Transactions On Power Electronics, vol. 19, pp. 508-514, March 2004.

[11] L. Marconi, F. Ronchi, and A. Tilli, "Robust nonlinear control of shunt active filters for harmonic current compensation," Automatica, vol 43, pp. 252-263, February 2007.

[12] S. Iyer, A. Ghosh, and A.Joshi, "Inverter topologies for DSTATCOM applications - a simulation study," Electric Power Systems Research, vol 75, pp.161-170 August 2005.

[13] A. Chaoui , J.P. Gaubert, and F. Krim, "Power quality improvement using DPC controlled three-phase shunt active filter," Electric Power Systems Research, vol 80, pp. 657-666, June 2010. 
[14] S. A. Verne, and María I. Valla, "Active power filter for medium voltage networks with predictive current control," Electric Power Systems Research, vol 80, pp. 1543-1551, December 2010.

[15] M.K. Syed, and B. V. S Ram, "Active power filtering in asymmetric power system by Modified Synchronous Detection Algorithm," IEEE Region Conference TENCON, pp. 1-4, November 2008.

[16] M.E. Meral, K. C Bayindir, and, M. Tumay, "Power quality improvement with an extended custom power park," Electric Power Systems Research, vol 79, pp. 1553-1560, November 2009.

[17] G. Bhuvaneswari, M.G. Nair, and S.K. Reddy, "Comparison of Synchronous Detection and I. Cos $\phi$ Shunt Active Filtering Algorithms," IEEE Conference on Power Electronic, Drives and Energy Systems, pp. 1-5, December 2006.

[18] E.E. Kholya, A.E. Sabbea, A.E. Hefnawya, and H. M Mharousb, "Three-phase active power filter based on current controlled voltage source inverter," International Journal of Electrical Power \& Energy Systems, vol 28, pp. 537-547 October 2006.

[19] P. Salmerón, R.S. Herrera and J. R. Vázquez , "A new approach for three-phase loadscompensation based on the instantaneous reactive power theory," Electric Power Systems Research, vol 78, pp. 605-617, April 2008.

[20] B. Singh, S.R. Arya, A. Chandra, and K.A. Haddad, "Implementation of adaptive filter based control algorithm for Distribution Static Compensator," IEEE Conference on Industry Applications Society Annual Meeting, pp. 1-8, Ocober 2012.

[21] A. Garces , M. Molinas, and P. Rodriguez,"A generalized compensation theory foractive filters based on mathematical optimization in ABC frame," Electric Power Systems Research, vol 90. pp. 1-10, September 2012.

[22] W.R.A. Ryckaert , J.A.L. Ghijselen, and J.A.A. Melkebeek, "Harmonic mitigation potential of shunt harmonic impedances," Electric Power Systems Research, vol. 65, pp. 63-69, November 2002

[23] "IEEE Recommended Practice and Requirements for Harmonic Control in Electric Power Systems 519-2014," - Redline Revision of IEEE Std 519-1992.

[24] L. Sainz, and J. Balcells, "Harmonic Interaction Influence Due to Current Source Shunt Filters in Networks Supplying Nonlinear Loads," IEEE Transactions On Power Delivery, vol. 27, pp. 1385 1393, July 2012.

[25] N.K. Kummari, A.K. Singh, and P. Kumar, "Comparative evaluation of DSTATCOM control algorithms for load compensation," IEEE Conference on Harmonics and Quality of Power, pp. 299-306, Decemember 2012.

[26] B. Singh, and S.R. Arya, "Composite observer-based contro algorithm for distribution static compensator in four-wire supply system," IET Power Electronics, vol. 6, pp. 251-260, June 2013.

[27] Y. S Jeon, N.H. Kwak, and J.B. Choo, "Analysis of Voltage Regulation by DSTATCOM Using the EMTDC Program," JPE, vol. 5,pp. 329-334 October 2005.

[28] S.R. Arya, and B. Singh, "CTF control algorithm of DSTATCOM for Power factor correction and zero voltage regulation," IEEE Conference on Sustainable Energy Technologies (ICSET), pp. 157 162, November 2012.

[29] G. Benysek, and M. Pasko, "Power Theories for Improved Power Quality," springer, 2012

[30] H. L. Jou, "Performance comparison of the three-phase activepower-filter algorithms," IEE Proceedings - Generation, Transmission and Distribution, vol. 142,pp. 646-652, August 2002.

[31] W. Shireen, and L. Taob "A DSP-based active power filter for low voltage distribution systems," Electric Power Systems Research, vol. 78, pp. 1561-1567, September 2008.

[32] C.E. Lin, C.L. Chen, and C.L. Huang, "Calculating approach and implementation for active filters in unbalanced three-phase system using synchronous detection method," IEEE Conference on Proceedings of International Conference on Industrial Electronics Control, Instrumentation and Automation, vol.1, pp. 374-380, August 2002.

[33] K. Anuradha, B.P. Muni, and A.D.R. Kumar, "Modeling of Electric Arc Furnace \& control algorithms for voltage flicker mitigation using DSTATCOM," IEEE Conference on Power Electronics and Motion Control , pp. 1123-1129, July 2009. 